\title{
UNA PROPUESTA DE METODOLOGÍA MULTIDIMENSIONAL EN LOS ESTUDIOS DE AUDIENCIA Y RECEPCIÓN
}

\section{A Proposal for Multidimensional Methodology in Audience and Reception Studies}

\section{Uma proposta de metodologia multidimensional nos estudos de audiência e recepção}

\author{
Jesús Bermejo-Berros, Universidad de Valladolid \\ lipsimedia@gmail.com
}

Recibido: 09 de julio de 2016

Aceptado: 31 de enero de 2017

\section{RESUMEN}

En la primera parte de este trabajo se argumenta acerca de la existencia de factores intrínsecos y extrínsecos que han venido influyendo en el tipo de producción científica al que han dado lugar los estudios de audiencia y recepción. De ello se han derivado formulaciones teóricas que tienen un conjunto de características que permiten distinguir entre teorías locales y globales. Se ilustra este fenómeno en el área del entretenimiento audiovisual. A partir de las limitaciones e insuficiencias detectadas en esas orientaciones se presenta, en la segunda parte, un modelo de investigación de recepción en advertainment que utiliza una metodología multidimensional, que unifica perspectivas fragmentadas en este campo. Este modelo describe una estructura que pone en relación factores antecedentes de diseño, variables moderadoras, dimensiones cognitivas, emocionales, corporales y comportamentales de procesamiento, así como efectos de eficacia publicitaria y entretenimiento. 


\title{
DISERTACIONES
}

Estudios de audiencias y recepción: audiencias minoritarias y nuevas mediaciones

ISSN: $1856-9536$

Doi: http://dx.doi.org/10.12804/revistas.urosario.edu.co/disertaciones/v11i1

Volumen 11, Número 1 / Enero-junio 2018

Versión PDF para imprimir desde

http://revistas.urosario.edu.co/index.php/disertaciones

Palabras clave: entretenimiento, eficacia publicitaria, metodología multidimensional, advertainment, videojuegos.

\begin{abstract}
In the first part of this paper we discuss the existence of intrinsic and extrinsic factors that have influenced the type of scientific production produced by studies of audience and reception. This production has given rise to theoretical formulations with a set of characteristics that distinguish local and global theories, a phenomenon that is illustrated in audiovisual entertainment. Based on the limitations and shortcomings detected in these orientations, the second section presents a reception research model in advertainment using a multidimensional methodology and unifying fragmented perspectives in this field. This model describes a structure that relates antecedent factors of design, moderating variables, cognitive, emotional, corporal, and behavioral dimensions of processing, as well as effects of advertising effectiveness and entertainment.
\end{abstract}

Keywords: Entertainment, advertising effectiveness, multidimensional methodology, advertainment, video games.

\section{RESUMO}

Na primeira parte deste trabalho argumenta-se acerca da existência de fatores intrínsecos e extrínsecos que têm vindo influindo no tipo de produção científica ao que têm dado lugar os estudos de audiência e recepção. Disso se têm derivado formulações teóricas que têm um conjunto de características que permitem distinguir entre teorias locais e globais. Se ilustra este fenômeno na área de entretenimento audiovisual. A partir das limitações e insuficiências detectadas nessas orientações, se apresenta, na segunda parte, um modelo de pesquisa de recepção em advertainment que utiliza uma metodologia multidimensional e que unifica perspectivas fragmentadas neste campo. Este modelo descreve uma estrutura que põe em relação fatores antecedentes de desenho, variáveis moderadoras, dimensões cognitivas, emocionais, corporais e comportamentais de processamento, assim como efeitos de eficácia publicitária e entretenimento.

Palavras-chave: entretenimento, eficácia publicitaria, metodologia multidimensional, advertainment, videojogos.

\section{Introducción: las relaciones de los estudios de audiencia y recepción}

Si la investigación de las audiencias y de la recepción comparten el objeto material de estudio, que consiste en el escudriñamiento de las respuestas de los usuarios de los medios de comunicación, de ahí su unidad como 


\section{DISERTACIONES}

ESTUDIOS

Estudios de audiencias y recepción: audiencias minoritarias y nuevas mediaciones

ISSN: 1856-9536

Doi: http://dx.doi.org/10.12804/revistas.urosario.edu.co/disertaciones/v11i1

Volumen 11, Número 1 / Enero-junio 2018

Versión PDF para imprimir desde

http://revistas.urosario.edu.co/index.php/disertaciones

campo de estudio, se diferencian en el tratamiento de su objeto formal. Los estudios de audiencias se interesan por la exposición a los medios y los hábitos de consumo, en ellos se busca cuantificar los consumos mediáticos mediante herramientas englobadas en la audimetría. A su vez, los estudios de recepción se interesan por aquello que hacen los usuarios con los contenidos mediáticos; intentan comprender los procesos, mecanismos y efectos de los medios a corto, medio y largo plazo tanto desde perspectivas comunicacionales, psicológicas individuales o colectivas, como desde aquellas de la sociología, la psicología social, la antropología o la perspectiva cultural.

Otro de los rasgos que caracterizan y distinguen a ambos tipos de estudios es su ámbito de aplicación y contexto de investigación. Los estudios de audiencia han estado siempre muy vinculados a las necesidades de los medios de comunicación de financiarse mediante contratos publicitarios. Por ejemplo, en países como España, donde solo el Estudio General de Medios (EGM) existía en la época del monopolio televisivo, se produce una irrupción de la audimetría, que apareció en la década de 1980, con la llegada de las televisiones comerciales al mercado audiovisual y, por tanto, con la introducción de la competencia audiovisual por la conquista de una mayor parte de la cuota del mercado. A partir de entonces, los estudios de audiencia son utilizados por los grupos audiovisuales como elemento de negociación de sus departamentos de mercadeo con los anunciantes, en los contratos por venta de espacios publicitarios. Los conceptos de rating, share y GRP's son conceptos clave en este tipo de estudios. Aun cuando han existido aproximaciones académicas a este tipo de estudios (Huertas, 2009; Cascajosa, 2016; Souza, 2014), el campo ha sido fuertemente influido por la aparición de empresas privadas especializadas en ellos (Nielsen, BARD o Kantar Media).

Por su parte, los estudios de recepción, principalmente desarrollados desde sectores académicos, han seguido un camino mucho más disperso, que responde más a interrogantes que hicieran avanzar el conocimiento en este campo (¿qué hace la audiencia con lo que consume? ¿qué es el entretenimiento?, etc.).

Un tercer rasgo que diferencia los estudios de audiencia de aquellos de recepción procede de los orígenes disciplinares. Los estudios de audiencia y recepción en países como España, han estado fuertemente influidos por los orígenes disciplinares que configuraron los estudios de comunicación en la década de 1970, integrados en las primeras facultades de Ciencias de la Información. La rama del periodismo, en el origen de esas facultades, se había nutrido a su vez de disciplinas de las humanidades como la filología, la semiótica o la historia e influyó considerablemente en el desarrollo de los planes de estudio iniciales, e indirectamente, en los programas de investigación del área de conocimiento de Comunicación Audiovisual y Publicidad, donde se desarrolla actualmente buena parte de la investigación en recepción, que ha recibido, más recientemente, la influencia de otras disciplinas de ciencias sociales como la psicología o la sociología.

En cambio, en otros países, como EE.uu., este campo ha estado más influido en sus orígenes por disciplinas de tradición más experimental como la psicología. Un tercer ejemplo de esta diversidad lo encontramos en Latinoamérica, donde aparecen otro tipo de estudios de recepción que giran en torno a los consumos enmarcados en factores ideológicos, culturales y sociales con figuras clave, que permiten entender el interesante volumen de trabajos en diferentes países como Colombia (Martín-Barbero \& Tellez, 2006), Mexico (Orozco, 2000; Padilla \& Orozco, 2006), Chile (Fuenzalida, 2006) y Brasil (Jacks \& Escosteguy, 2006).

Por último, respecto a los métodos de obtención de datos, los estudios de audiencia recogen respuestas de los públicos en términos de variables dicotómicas sencillas (por ejemplo si vio o no el programa). En cambio, los estudios de recepción indagan un mayor número de variables con complejidades diversas que requieren, en muchos casos, 


\section{DISERTACIONES}

ESTUDIOS

Estudios de audiencias y recepción: audiencias minoritarias y nuevas mediaciones

ISSN: 1856-9536

Doi: http://dx.doi.org/10.12804/revistas.urosario.edu.co/disertaciones/v11i1

Volumen 11, Número 1 / Enero-junio 2018

Versión PDF para imprimir desde

http://revistas.urosario.edu.co/index.php/disertaciones

utilizar metodologías de recopilación de datos de tipo empírico o experimental. Es de destacar el escaso número de investigaciones de estudios de recepción en comparación con el volumen total de investigaciones en comunicación. Así, en un estudio llevado a cabo con los 339 artículos publicados entre 2004 y 2013 en la Revista Latina de Comunicación Social, que se caracteriza por ser una publicación que recoge una amplia muestra de estudios de comunicación en sus diferentes campos y especialidades, se constata que apenas hay estudios de recepción propiamente dichos (Bermejo, 2014). El análisis del corpus de artículos de ese trabajo muestra que la mayoría de las técnicas utilizadas en comunicación son el análisis de contenido o el análisis secundario, que no pueden considerarse estudios de recepción propiamente dichos. El tercer tipo de técnica más utilizada es el cuestionario, y solo una parte de las investigaciones de la muestra entraría dentro del campo de la recepción en sentido laso. Solamente 5 de los 339 artículos de la muestra son estudios de recepción con metodologías empíricas (2) o experimentales (3) (Igartua, 2013; Soto-Sanfiel, Aymerich-Franch \& Ribes-Guàrdia, 2009).

A partir de los rasgos anteriores cabe preguntarse: ¿cuáles son los actuales desafíos que ambas tradiciones investigativas afrontan en la actualidad?, y ¿cuáles son las respuestas que están aportando?

Los estudios de audiencia se encuentran hoy confrontados a la necesidad de encontrar soluciones para adaptarse a los diversos fenómenos asociados a la evolución del propio medio de comunicación y a los cambios técnicos, tecnológicos y socioculturales de la revolución digital, donde parte de los cambios en los modelos de medición de audiencias obedece al uso de internet como protocolo de difusión y consumo mediático, pero también por otros factores como el paso de la televisión analógica a la digital, la diversificación de pantallas y tipos de consumo, la migración de la audiencia de los media clásicos, la saturación publicitaria y su falta de eficacia, las nuevas plataformas de contenidos, la televisión social, el Big Bata, etc. Este nuevo contexto ha llevado a las televisiones a un estado de dificultad y de crisis en la medición de audiencias. Uno de los factores en los que más está trabajando la audimetría actual, para solventar esta situación, es el intento de medir el consumo real de los productos televisivos teniendo en cuenta que el consumo lineal en directo es ya solo uno entre otros posibles y el no lineal crece año tras año. Los live+SD ya no dan cuenta del consumo televisivo, en particular de las series de ficción, y dejan fuera el uso del Digital Video Recorder (DVR), ignoran el streaming y el Video on Demand VOD. Las operadoras de medios han de desarrollar estrategias transmedia y crossmedia si quieren seguir gozando de la confianza de los anunciantes publicitarios, que siguen siendo su fuente principal de financiación. Hay así un intento por medir las audiencias televisivas multipantalla (Extender Tv). Un ejemplo de esas tentativas es el acuerdo entre Comscore y Kantar para medir las audiencias crossmedia a partir de 2017 mediante el Cross Media Audience Measurement (смам), herramienta que pretende medir el denominado total media, que incluye la medición de la televisión lineal, la no lineal, el vídeo digital y la navegación por páginas web y aplicaciones móviles. Un paso más allá correspondería al total view que incluiría la medición no solo de contenidos audiovisuales sino también de textos e imágenes (Fernández, 2016).

Aun cuando pueden constatarse las diferencias en el tratamiento del objeto formal por los estudios de audiencia y de recepción, existen actualmente desafíos comunes. Uno de ellos es la necesidad de incorporar en sus procedimientos de indagación y en sus conceptualizaciones teóricas, los conceptos de participación (Bergillos, 2015, Quintas \& González, 2015) e interactividad (Jensen, 1998; Kaminova, 2010; Kiousis, 2002; Koolstra \& Boss, 2010; Landay, 2014; Rafaeli, 1988; Steuer, 1995). Otro de los desafíos, de gran relevancia si queremos aspirar a construir una teoría integrada de la recepción, es la búsqueda de metodologías de investigación que permitan pasar de la 


\section{DISERTACIONES}

ESTUDIOS

Estudios de audiencias y recepción: audiencias minoritarias y nuevas mediaciones

ISSN: 1856-9536

Doi: http://dx.doi.org/10.12804/revistas.urosario.edu.co/disertaciones/v11i1

Volumen 11, Número 1 / Enero-junio 2018

Versión PDF para imprimir desde

http://revistas.urosario.edu.co/index.php/disertaciones

fragmentación actual de la respuesta de los sujetos receptores a una metodología que integre componentes de su respuesta multidimensional a los productos mediáticos.

\section{De la fragmentación a la necesidad de integraciones multidimensionales en los estudios de recepción}

Si los estudios de audiencia tienen trazado un programa de desarrollo para afrontar las nuevas exigencias planteadas a la audimetría, los estudios de recepción, por su mayor diversidad, no tienen uno sino diferentes frentes de indagación en función de parámetros tan diversos como el tipo de medio (TV, Internet, videojuegos, redes sociales...) o el tópico de estudio (la información, la publicidad, el entretenimiento...), cada uno con sus propias peculiaridades. No obstante, todos ellos tienen planteado un reto a futuro que tiene que ver con la necesidad de integrar la actual fragmentación en el estudio del receptor mediático. Por razones de espacio, nos detendremos en la exposición de dos de ellos que ilustran este fenómeno de fragmentación. Por un lado, aquellos factores que están condicionando la producción científica en este campo y por otro, los factores que conducen a proponer teorías locales de recepción.

\section{Factores intrínsecos y extrínsecos de la producción científica en los estudios de audiencia y recepción}

La producción científica está condicionada por factores extrínsecos e intrínsecos. Los primeros se refieren al sistema de publicación y difusión de resultados imperante en la comunidad científica. Como hemos analizado en otro lugar (Bermejo, 2012), la progresiva concentración editorial en cinco grandes grupos editoriales en el campo de la comunicación, los sistemas imperantes de indexación que repercuten en el reconocimiento y visibilidad de los trabajos publicados y los tópicos de investigación dominantes en el mundo global anglosajón, no siempre coincidentes con los de otros entornos culturales (francófonos, hispanófonos...), hace que vayan imponiéndose determinados estándares de edición, tanto en los modelos de presentación, como en los tópicos dominantes como en las limitaciones en la extensión máxima de los trabajos, que no han de superar en la mayoría de los casos las 8000 palabras aproximadamente. Este primer tipo de condicionantes extrínsecos influyen a su vez sobre los factores intrínsecos. Estos corresponden a las dificultades inherentes a los propios estudios de recepción. Hoy comenzamos a entender la complejidad de las respuestas de recepción mediáticas en las que participan numerosos mecanismos mentales. Dado que los factores extrínsecos de producción científica influyen sobre estos factores intrínsecos, la investigación en recepción, para poder adaptarse a las exigencias de publicación, ha tendido a fragmentar la respuesta del receptor. A medida que la investigación ha ido acumulando conocimiento durante décadas sobre el receptor, hemos ido entendiendo esa complejidad que ha llevado en algunos casos a establecer determinadas etiquetas (el receptor pasivo dio paso al receptor activo; el redescubrimiento de la emoción vino a transformar al receptor cognitivo y procesador de información; las neurociencias han añadido nuevos aspectos del procesamiento mental; etc.). Paradójicamente, esta mayor constatación de la complejidad del receptor ha engendrado mayores fricciones entre los condicionantes extrínsecos y estos condicionantes intrínsecos, emanados del propio avance epistemológico de los estudios de recepción. Ese necesario equilibrio y correspondencia entre estos dos tipos de factores no está al día de hoy resuelta, aun cuando existen 


\section{DISERTACIONES}

ESTUDIOS

Estudios de audiencias y recepción: audiencias minoritarias y nuevas mediaciones

ISSN: 1856-9536

Doi: http://dx.doi.org/10.12804/revistas.urosario.edu.co/disertaciones/v11i1

Volumen 11, Número 1 / Enero-junio 2018

Versión PDF para imprimir desde

http://revistas.urosario.edu.co/index.php/disertaciones

algunas voces que abogan por introducir otras formas de circulación de los resultados científicos de la investigación (como son los repositorios y otros recursos de almacenamiento de información ya disponibles desde un punto de vista técnico pero condicionados por los intereses de los grupos empresariales que controlan la distribución editorial). En este contexto, y como ilustración de aquello a lo que se ven impelidos los investigadores de la recepción, tomaremos el importante tópico del estudio del entretenimiento mediático.

Como hemos descrito en otro lugar (Bermejo, 2013b), los estudios consagrados a indagar los mecanismos explicativos del entretenimiento audiovisual en las últimas tres décadas pueden agruparse, según proponen Jennings Bryant y Peter Vorderer (2006), en tres tipos de investigaciones:

a) Una que se interesa por los procesos preparatorios y de recepción. Dentro de estos se han indagado tanto aquellos procesos que conducen a exponerse al entretenimiento (la motivación, la exposición selectiva), como aquellos procesos cognitivos básicos (atención, percepción, comprensión, memoria, aprendizaje).

b) Otra se interesa por los procesos de respuesta. Aquí encontramos, por un lado, tópicos de investigación como el estudio de las reacciones del sujeto ligadas a la fantasía y la imaginación, la identificación y la empatía, la implicación (involvement), las reacciones emocionales discretas (como el miedo o la sorpresa) o las interacciones parasociales. Por otro lado, encontramos otro grupo de tópicos que se interesan por las respuestas de los sujetos en función de alguna propiedad del producto audiovisual. Así encontramos el estudio de las reacciones a diferentes tipos de productos audiovisuales caracterizados por el horror, la violencia, el humor o la pornografía. En tercer lugar, dentro de esta segunda área habría que incluir también las actuales indagaciones en relación a un conjunto de nuevos conceptos que dan cuenta de la experiencia del sujeto durante la exposición al producto audiovisual. Entre estos cabe destacar los de inmersión, realismo percibido (perceived realism), transportación (transportation), enganche (engagement) y presencia (presence) (Bermejo \& Soto-Sanfiel, 2011).

c) Si los dos primeros campos vienen a recoger información sobre lo que ocurre cuando nos exponemos a una experiencia de entretenimiento y el proceso de disfrute que de ello se deriva, hay, en tercer lugar, un área que se interesa por las aplicaciones. Aquí cabe citar aquellas investigaciones que indagan sobre aquello que ocurre en situaciones de hibridación de géneros (advertainment y advergaming), como es el caso del product placement y otras formas de nueva publicidad enmascarada (Bermejo, 2013a; Shrum, 2004) donde la experiencia de entretenimiento trae aparejada la presencia de alguna forma de publicidad (Bermejo, 2013b).

\section{Teorías locales y globales del entretenimiento audiovisual}

Un segundo factor, derivado del anterior, que ilustra la fragmentación de los estudios de recepción, está en los modelos teóricos propuestos. Tomemos nuevamente el ejemplo bien ilustrativo del entretenimiento mediático. Como hemos defendido en otro lugar, las diferentes perspectivas metodológicas en el estudio del entretenimiento audiovisual pueden ser agrupadas en estudios indirectos o directos. En los primeros, se incluyen estudios de diferente naturaleza desde diversas disciplinas de las ciencias sociales y humanas (la narratología, la semiótica del cine, la psicología ontogenética, la teoría estética, etc.). Los estudios directos del entretenimiento mediático, mediante metodologías empíricas y experimentales, han dado lugar a numerosas teorías locales del entretenimiento. Así, para 


\section{DISERTACIONES}

ESTUDIOS

Estudios de audiencias y recepción: audiencias minoritarias y nuevas mediaciones

ISSN: 1856-9536

Doi: http://dx.doi.org/10.12804/revistas.urosario.edu.co/disertaciones/v11i1

Volumen 11, Número 1 / Enero-junio 2018

Versión PDF para imprimir desde

http://revistas.urosario.edu.co/index.php/disertaciones

Klimmt y Vorderer (2009) habría entre estas, aquellas que se centran en experiencias específicas del receptor. Por ejemplo, las teorías del suspenso (Vorderer, Wulff \& Friedrichsen, 1996), la sorpresa (Bermejo \& López, 2013a), el miedo (Cantor, 2011) y la gestión del estado de ánimo (Knoblock, 2006). También serían teorías locales aquellas vinculadas con procesos cognitivos particulares como las teorías sobre la imaginación y la fantasía (Valkenburg \& Jochen, 2006) o la identificación con los personajes (Cohen, 2010). Como señala Vorderer (2003)

la combinación de estas teorías particulares, que tienen relaciones entre sí, no constituyen, en sentido estricto, partes de una teoría general. Sin embargo, establecen un programa de investigación que guía y orienta las propuestas metodológicas y de investigación en el campo del entretenimiento (p. 134).

Si la investigación en los tres tópicos referidos por Bryant y Vorderer (2006), descritos más arriba, ha dado lugar a diferentes teorías locales del entretenimiento, estas se han visto influenciadas, de manera relevante, por las investigaciones de Dolf Zillmann y su equipo. Por ejemplo, entre ellas pueden citarse la teoría de la exposición selectiva (selective exposure) según la cual el receptor decide disfrutar de un producto de entretenimiento u otro en función de su actual estado de ánimo. Hay pues una exposición determinada por un factor hedonista. En la teoría del manejo del estado de ánimo (mood management) (Zillmann, 1988; Beth, 2003), la persona busca regular su estado de ánimo de tal modo que espera tener un estado de ánimo positivo durante la exposición e intenta hacer desaparecer los estados de ánimo negativos. Desde estas perspectivas, el entretenimiento audiovisual tiene un carácter de regulador emocional y tendría la función de gratificador emocional -concepción que tiene elementos en común con la teoría de usos y gratificaciones postulada inicialmente por Elihu Katz y Jay Blumler-. Otra teoría local es la de disposición de afecto (affective disposition) en la que se toma en consideración el mecanismo de empatía que se activa durante la experiencia de entretenimiento narrativo (Raney, 2006). La activación de la empatía hace que el receptor evalúe a los personajes en términos de su conducta moral y con base en ello toma partido por unos u otros personajes. El resultado de ese proceso de empatía positiva o negativa hacia los personajes hace que el receptor active estados afectivos de deseo o de inquietud sobre el desenlace final de la historia para los personajes. Como consecuencia de todo este proceso de relación con los personajes, el espectador adquiere disposiciones de ánimo que influirán sobre futuras exposiciones a otros productos de entretenimiento similares. Una cuarta teoría es la de la transferencia de la excitación (Bryant \& Miron, 2003), que parte del fenómeno neurofisiológico de activación cortical. Cuando nos exponemos a un producto de entretenimiento experimentamos un proceso de activación cortical. Esta teoría ha aportado apoyo experimental que muestra que esa excitación cortical (arousal) se mantiene activa tras la finalización de la exposición audiovisual que irá disminuyendo poco a poco. Si el espectador es expuesto a un nuevo estímulo audiovisual, antes de que haya desaparecido la excitación cortical anterior, se produce un fenómeno de transferencia de excitación al nuevo producto de entretenimiento. Sin que podamos entrar en ello, han sido formuladas otras teorías como la teoría de la dinámica afectiva (Zillmann, 2003), la trifactorial (Bryant \& Miron, 2003), la teoría de las relaciones parasociales (parasocial relationships), que postula el vínculo de implicación del espectador con los personajes a largo plazo (Klimmt, Hartmann \& Schramm, 2006), la teoría interactiva (Interactive entertainment theory) (cf. Klimmt \& Vorderer, 2009) o el conjunto de ocho teorías de los efectos que hemos descrito en otro lugar tales como la teoría social cognitiva, la catarsis fruicional o la teoría postural (Bermejo, 2005). Por otro lado, como señala Peter Vorderer (2003), existen aspectos de la recepción que no han sido incluidos en estas teorías parciales y que deberíamos incorporar "tales como el papel que 


\section{DISERTACIONES}

ESTUDIOS

juegan los afectos negativos, aspectos no ya psicológicos sino sociales como la diversidad cultural e individual, o como último ejemplo, el papel de los nuevos medios interactivos" (p. 135).

Con respecto a las teorías globales del entretenimiento, apenas existen propuestas y son más escasas aún aquellas que vengan acompañadas de suficiente soporte empírico que las valide. En la teoría general propuesta por Klimmt y Vorderer (2009) action-theoretical framework, junto a las dimensiones afectivas de otros modelos, se añade el factor comunicacional de la experiencia de disfrute que incluye la "motivación, las expectativas y otros procesos cognitivos de procesamiento de la información generados durante la exposición al entretenimiento, los procesos de activación cortical, las variables conductuales y la relevancia del entretenimiento en nuestro bienestar en la vida cotidiana" (Klimmt \& Vorderer, 2009, pp. 348-349). A pesar de su interés, esta teoría mantiene aún diferentes enunciados metateóricos que habrán de ser validados así como la búsqueda de conexiones teóricas y empíricas con otras dimensiones del receptor de naturaleza emocional, corporal y conductual. Por tanto, como hemos señalado en otro lugar, "la validación del conjunto teórico, a partir de la indagación de las partes separadas, introduce sesgos metodológicos que dificultan la extrapolación de resultados y por tanto arroja incertidumbres que permitan confortar la fundamentación de la teórica general” (Bermejo, 2013b, p. 714).

En definitiva, cada una de las teorías locales analiza dimensiones específicas del fenómeno del entretenimiento, bien algún tipo de reacción afectiva o corporal, o bien algún proceso cognitivo. Los ejemplos de teorías locales correspondientes a esas tres dimensiones aparecen en rojo, azul y gris respectivamente en la figura 1. A esa triple dimensión del entretenimiento cabría incorporar una cuarta de naturaleza ya no individual sino social que se interesa por el entretenimiento en el seno de los grupos sociales y los diferentes contextos culturales.

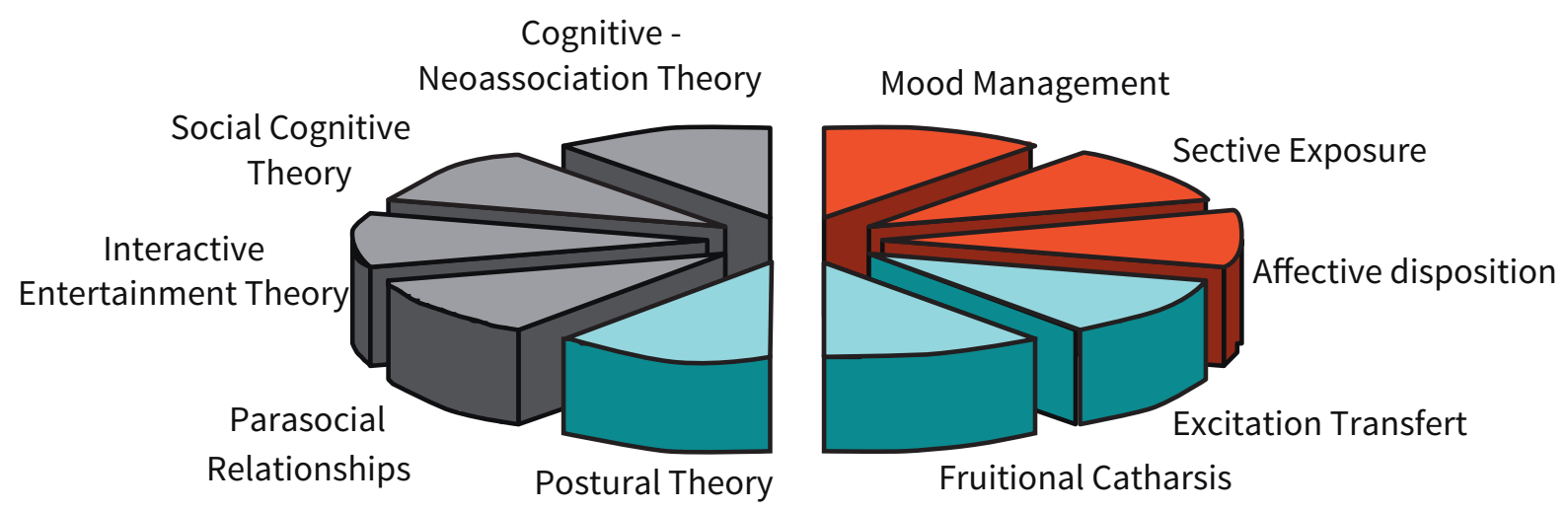

Figura 1. Algunas teorías locales del entretenimiento audiovisual

En consecuencia, a día de hoy, no puede hablarse de una teoría general del entretenimiento en la medida en que todavía no se han articulado todas esas diferentes dimensiones que atienden a factores parciales de la emoción, la cognición, la respuesta corporal o social, en una teoría de la recepción integrada. Aun hemos de avanzar hacia investigaciones multidimensionales que permitan coordinar en una teoría de conjunto los distintos procesos de recepción, que sean capaces de este modo de aprehender la complejidad de la experiencia del entretenimiento. A lo anterior se une otro factor que ha contribuido a mantener la fragmentación en el estudio del 


\section{DISERTACIONES}

ESTUDIOS

Estudios de audiencias y recepción: audiencias minoritarias y nuevas mediaciones

ISSN: 1856-9536

Doi: http://dx.doi.org/10.12804/revistas.urosario.edu.co/disertaciones/v11i1

Volumen 11, Número 1 / Enero-junio 2018

Versión PDF para imprimir desde

http://revistas.urosario.edu.co/index.php/disertaciones

receptor, pues una parte del esfuerzo de los investigadores del campo se ha orientado hacia el estudio de nuevos tópicos y temas de estudio, trasladando a estos las mismas metodologías de las teoría locales. Ello contribuye a que los problemas de integración se mantengan y no se avance hacia una teoría integrada y multidimensional del entretenimiento y la recepción. Este estado del campo de la recepción nos ha conducido a proponer e indagar en una vía metodológica que incluye, en una misma investigación, variables dependientes de cada una de esas tres dimensiones - cognitivas, emocionales y corporales-, que participan simultáneamente en este complejo fenómeno de la experiencia estética del entretenimiento (Bermejo, 2013b). Esta propuesta no constituye una nueva teoría local (o general), sino una metodología que permita explorar vías experimentales que permitan avanzar hacia una futura teoría general de la recepción.

\section{La metodología multidimensional en la respuesta a los mensajes híbridos del advertainment}

En esta segunda parte presentamos una propuesta que describe un modelo de metodología multidimensional aplicado a la investigación de los "mensajes híbridos" del advertainment en los que se fusiona el entretenimiento y la publicidad. Estos han sido definidos como "todo intento pagado de influir a la audiencia para obtener beneficios comerciales utilizando comunicaciones que presentan un carácter no comercial" (Balsubramanian, 1994, p. 30). El advertainment es definido como "aquellas prácticas promocionales que integran las comunicaciones de la marca dentro del contenido de los productos de entretenimiento" (Russell, 2007, p. 3). En función del grado de integración de la publicidad en el contenido de entretenimiento encontramos diferentes modalidades de advertainment tales como el product placement o el branded entertainment (Hudson \& Hudson, 2006; Russell, 2007).

Hasta ahora, la eficacia publicitaria del advertainment se ha estudiado fundamentalmente en relación con las características de diseño de los antecedentes como variables independientes (Martí, 2011). En primer lugar, se ha buscado entender y establecer relaciones funcionales y/o causales entre esos antecedentes y sus efectos publicitarios a nivel cognitivo, afectivo y conativo. En segundo lugar, desde el punto de vista del procesamiento de los antecedentes por el receptor, se han estudiado sobre todo aspectos cognitivos (modelo de Balasubramanian, Karrh \& Patwardhan,2006) y, de manera aislada, tanto las reacciones corporales vinculadas a la emoción (registros del sistema nervioso periférico), como las conductuales (i.e. navegación durante el juego). En tercer lugar, desde el punto de vista de los efectos, se ha prestado atención sobre todo a los efectos de eficacia publicitaria (EF) según la distinción clásica entre efectos cognitivos, afectivos y conativos. Sin embargo, estos no han sido analizados conjuntamente con los fenómenos de entretenimiento (ENT) que tienen lugar durante el período de exposición a los estímulos publicitarios emplazados. Ahora bien, para avanzar en el conocimiento del advertainment es necesario integrar el conjunto de esos estudios parciales de los factores intervinientes anteriores en un todo coherente. En respuesta a ello proponemos un modelo de metodología multidimensional que hemos implementado para el estudio de los mensajes híbridos del advertainment, cuya estructura aparece recogida en la figura 2. Los antecedentes corresponden a todas aquellas variables independientes que intervienen en el procesamiento del contenido de entretenimiento. Según el modelo, en el proceso de exposición al contenido de entretenimiento, hay que considerar un conjunto de variables que podemos agrupar en dos conjuntos de factores. En los antecedentes 


\section{DISERTACIONES}

ESTUDIOS

Estudios de audiencias y recepción: audiencias minoritarias y nuevas mediaciones

ISSN: 1856-9536

Doi: http://dx.doi.org/10.12804/revistas.urosario.edu.co/disertaciones/v11i1

Volumen 11, Número 1 / Enero-junio 2018

Versión PDF para imprimir desde

http://revistas.urosario.edu.co/index.php/disertaciones

de diseño (VD) encontramos todas aquellas tomas de decisión acerca de las propiedades de la publicidad que se integra en el contenido de entretenimiento (qué, cómo, dónde y para qué). Entre los antecedentes encontramos también un segundo factor formado por un conjunto de variables moderadoras (VM), presentes en el individuo con anterioridad al procesamiento del contenido objeto de estudio y que influyen sobre su respuesta actual a este. El procesamiento corresponde a aquellas variables de respuesta del sujeto durante el proceso de exposición al contenido de entretenimiento (respuesta en línea). Durante la actividad de juego el participante pone en funcionamiento numerosos procesos mentales (de atención, perceptivos, conocimientos, habilidades, razonamiento, memoria, etc.) y comportamentales. Sin embargo, en el presente modelo son retenidos para su medición aquellos de atención y perceptivos que permiten testar directamente los factores de diseño publicitario (PER). Así, el eye tracker permite evaluar si el estímulo publicitario ha llegado al sistema atencional-perceptivo del jugador. En segundo lugar se evalúan las reacciones emocionales-corporales experimentadas por el jugador durante la partida (el biofeeback recoge las señales del SNP). En tercer lugar, se incluye en el procesamiento la actividad conductual de navegación del sujeto durante el juego. En ella se despliega la conducta participativa e interactiva del sujeto. Este último análisis tiene el interés de mostrar el grado de interacción del jugador con el producto/marca emplazado, lo que permite determinar el grado de integración narrativa de la marca en el juego en cada jugador. Entendemos aquí el concepto de interactividad en el sentido de aquella actividad recíproca, simultánea, mutua, interrumpible (Kiousis, 2002; Koolstra \& Boss, 2010; Landay, 2014; Rafaeli, 1988;), que establece un sistema de relación (Kaminova, 2010). En ella el usuario tiene la capacidad de modificar el contenido en tiempo real (Jensen, 1998; Steuer, 1995). Por último, los efectos son aquellas variables dependientes que resultan del procesamiento del estímulo audiovisual de entretenimiento. Son variables de respuesta cognitiva, actitudinal y conductual, que son medidas con posterioridad a la exposición al contenido de entretenimiento (respuestas off-line).

El funcionamiento de la estructura descrita en la figura 2, que pone en relación los diferentes factores (Antecedentes $\rightarrow$ Procesamiento $\rightarrow$ Efectos), no es secuencial sino cíclico, de tal forma que cada variable es activada y da lugar a un procesamiento del sujeto con sus consiguientes efectos cuando aparecen los estímulos desencadenantes (vi) durante el proceso de exposición al contenido.

Teniendo en cuenta que los mensajes híbridos del advertainment son construidos con el objeto de influir sobre el receptor, la dinámica de conjunto del modelo de metodología multidimensional tiene como finalidad indagar si los factores de diseño producen eficacia publicitaria, así como determinar la manera en que el resto de variables del sistema en su conjunto contribuyen a favorecer (o no) el resultado persuasivo publicitario esperado desde el diseño.

En lo que sigue, se presentan los elementos del diseño experimental de una investigación de recepción en la que se utilizó esta metodología multidimensional que integra en una misma investigación el conjunto de factores que venimos de evocar. Ello significa que, en el procedimiento experimental de una misma investigación se recogen respuestas del sujeto en cada una de las variables de todos esos factores y variables antecedentes, de procesamiento y efectos. 


\section{DISERTACIONES}

ESTUDIOS

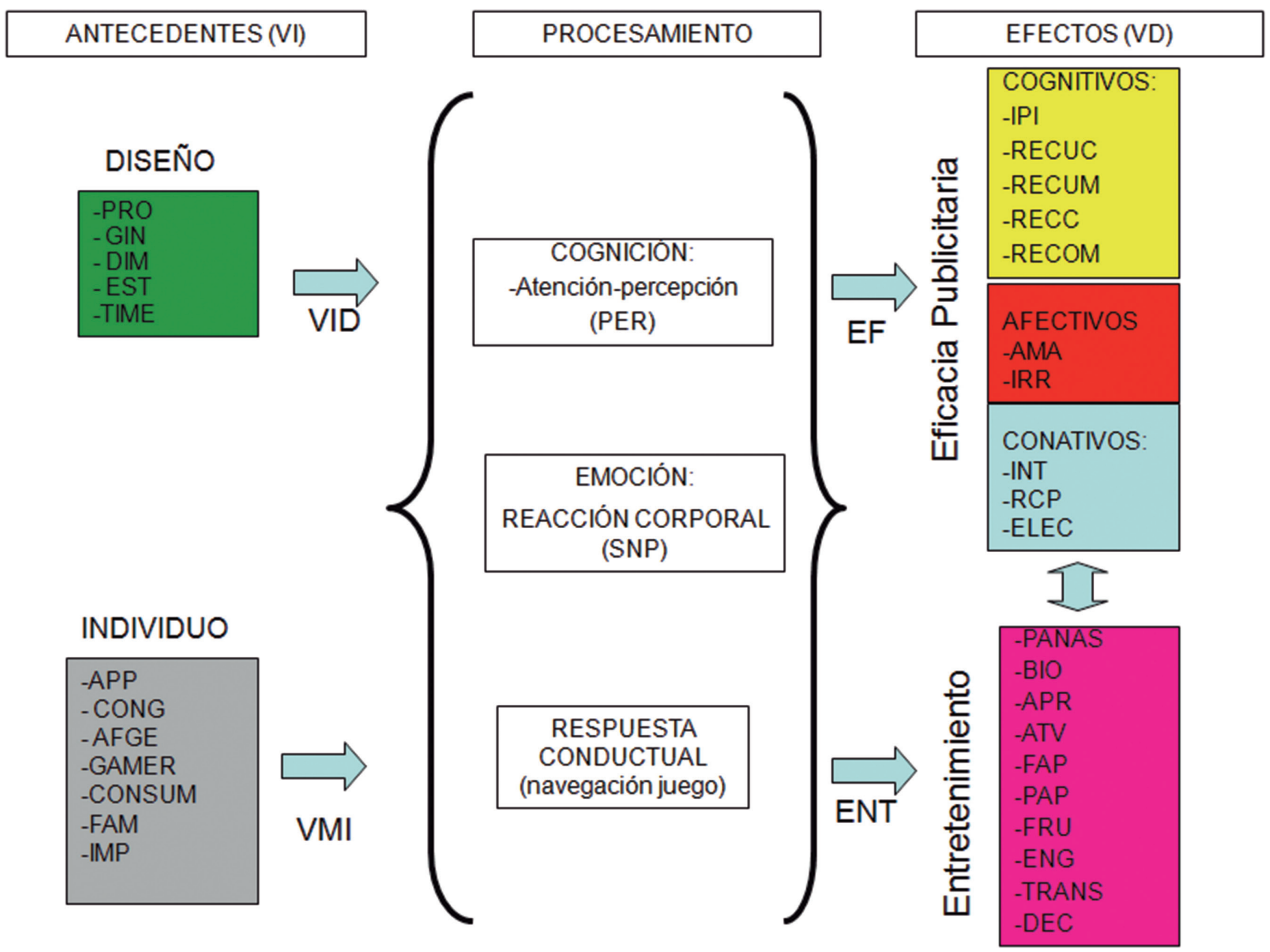

Figura 2. Estructura del Modelo de Metodología Multidimensional en el estudio de recepción de los mensajes híbridos del Advertainment (vi: Variables Independientes; vм: Variables Moderadoras; EF: Eficacia Publicitaria; ENT: Entretenimiento).

\section{Elementos metodológicos en la respuesta multidimensional al emplazamiento de marca en entretenimiento audiovisual interactivo: el videojuego ${ }^{1}$}

La finalidad de este apartado no es dar cuenta de los resultados obtenidos en la investigación descrita a continuación sino ilustrar, mediante un ejemplo concreto, el modo en que se puede implementar, de manera viable y efectiva, la metodología multidimensional en los estudios de recepción. Esta investigación fue desarrollada en el laboratorio

1 Esta investigación ha sido financiada por el Ministerio de Economía y Competitividad de España, dentro del Plan Nacional I+D+i (Proyecto CSO2013-42506-R del que el autor es IP). Proyecto EFIVIDEM: Eficacia del emplazamiento de producto e interactividad en videojuegos y aplicaciones empresariales. 


\section{DISERTACIONES}

ESTUDIOS

Estudios de audiencias y recepción: audiencias minoritarias y nuevas mediaciones

ISSN: 1856-9536

Doi: http://dx.doi.org/10.12804/revistas.urosario.edu.co/disertaciones/v11i1

Volumen 11, Número 1 / Enero-junio 2018

Versión PDF para imprimir desde

http://revistas.urosario.edu.co/index.php/disertaciones

Lipsimedia ${ }^{2}$ e integra la respuesta participativa e interactiva del receptor, así como componentes de respuesta multidimensional de variables cognitivas, afectivas, psicofisiológicas y comportamentales. Se trata de una investigación de advertainment con videojuegos, contenido de entretenimiento que permite la integración de todos los aspectos del receptor anteriores, en respuestas multidimensionales. Esta investigación conecta dos campos de estudio frecuentemente tratados de manera separada - la eficacia publicitaria del emplazamiento de producto (EF), abordada generalmente desde el mercadeo y el entretenimiento audiovisual interactivo (ENT), desde la psicología de los medios (media psychology)-. Este estudio tiene una doble dimensión teórica y aplicada, pues proporcionará conocimiento científico básico sobre el funcionamiento de la publicidad en videojuegos e informará a la empresa de las posibilidades efectivas que tiene su juego para emplazar publicidad. Adicionalmente, busca aportar conocimiento básico sobre el entretenimiento audiovisual y sus eventuales vínculos con la eficacia publicitaria. Al mismo tiempo, a la empresa le aportará información sobre el grado de entretenimiento que aporta su videojuego.

La perspectiva que adoptamos en esta investigación tiene en consideración el hecho de que jugar videojuegos es una actividad cultural compleja en la que, para entender la eventual eficacia de la publicidad emplazada, es necesario tener en cuenta no ya las variables de diseño y moderadoras del sujeto, sino los efectos que se producen durante el juego en las variables de entretenimiento. Asimismo, la metodología multidimensional propuesta permite testar si el entretenimiento es susceptible de actuar como factor moderador de la eficacia publicitaria.

\section{Objetivos, técnica y procedimiento experimental}

Para esta investigación se ha utilizado una adaptación del videojuego The Guest del estudio independiente Team $G$ tham ${ }^{3}$. Se trata de un videojuego ambientado en un hotel de EE.Uu. en los años 80 . Es un juego de exploración en primera persona: el jugador se encuentra en una habitación, debe explorarla y conseguir determinados indicios y objetos para salir de ella. Por tanto, ha de participar e interactuar con elementos del juego a través de su avatar.

El diseño general de esta investigación, tal y como queda sintetizado en la figura 2, persigue indagar la influencia de un conjunto de variables independientes o factores antecedentes de diseño (vi) y de un conjunto de variables moderadoras o factores antecedentes individuales (vM) sobre las variables dependientes de eficacia publicitaria (EF) y las variables dependientes de entretenimiento experimentado por la exposición al videojuego (ENT). Se trata asimismo de indagar las relaciones mutuas entre el entretenimiento y la eficacia publicitaria (ENT <---> EF).

Tenemos por tanto dos objetivos generales. El primero es indagar si el tipo de marca emplazada (TIME) y otras variables publicitarias producen efectos diferenciales en eficacia publicitaria (VI--> EF). El segundo,conocer si existe alguna relación entre el grado de entretenimiento experimentado durante el juego y la eficacia publicitaria resultante de esa actividad (ENT --> EF).

Por otro lado, si en este diseño experimental las variables dependientes constituyen efectos de procesamiento off-line (las respuestas se generan en un tiempo no coincidente con el juego), también se miden tres tipos de variables de procesamiento en línea del jugador, es decir, aquellas respuestas que tienen lugar durante la partida y en relación con ella -1 . variables cognitivas de tipo atencional y perceptivo mediante registro de eye tracker de toda

2 Lipsimedia: Laboratorio de Investigación de Publicidad y Psicología de los Media. Universidad de Valladolid.lipsimedia@gmail.com; investigacion.lipsimedia@gmail.com

3 http://www.teamgothammadrid.com/theguest/ 


\section{DISERTACIONES}

ESTUDIOS

la partida del jugador; 2. variables corporales mediante registros psicofisiológicos del sistema nervioso periférico con biofeeback (EMG, EEG, conductancia de la piel y actividad electrodermal, motilidad, volumen BVP y amplitud sanguínea PVA, temperatura); 3. variables comportamentales de navegación del jugador en el videojuego mediante grabación completa de su partida-.

En cuanto al procedimiento experimental, el participante juega de manera individual el videojuego The Guest durante 15 minutos. Esta duración ha sido establecida en pretesteos previos que han permitido determinar cuál es el tiempo medio requerido por un jugador para ser susceptible de ser expuesto a los dos estímulos seleccionados. El sujeto juega el videojuego en una cabina acondicionada del laboratorio Lipsimedia, en un ordenador de 24' HD.

Por otro lado, dado el número de variables incluidas en el diseño experimental, un aspecto importante en esta investigación era testar previamente la cantidad y distribución de las pruebas que el sujeto podía realizar durante la investigación sin que interfirieran otros factores que distorsionasen las respuestas del sujeto (como la fatiga). Se realizaron diferentes pruebas previas que permitieron seleccionar el conjunto de variables retenidas para la investigación, que fueron distribuidas en dos sesiones experimentales separadas por una semana. La primera sesión tuvo una duración de 45 minutos y la segunda de 30.

Para esta investigación se realizaron cinco versiones del videojuego y los participantes fueron asignados a ellas de manera aleatoria. En cuatro de las versiones se introdujeron en el videojuego dos estímulos, uno estático y otro dinámico e interactivo. El estático fue un póster colocado en una de las paredes de la habitación. El objeto dinámico fue una botella de whisky que se encontraba en un armario y a la que el sujeto podía acceder durante el juego, cogerla e incluirla en la historia. El póster y la botella corresponden a marcas de whisky con referente diegético de la misma categoría. Ambos objetos fueron diseñados para integrarse tanto en la estética del juego como en su narrativa (pueden verse estos estímulos en Bermejo \& Gil, 2016). La variable que definió cada uno de los cuatro grupos experimentales fue el tipo de referente, real o ficticio: MR (marca real), ME (marca enmascarada), MF (marca ficticia), мı (marca incongruente). Las marcas reales fueron seleccionadas en función de criterios de venta y consumo. El quinto fue el grupo control, en el que no se incluyeron los estímulos y corresponde al juego original.

Las imágenes del anexo 1 en Bermejo y Gil (2016) muestran estos dos objetos dentro del videojuego. La figura 3 muestra las marcas introducidas en los dos objetos estimulantes dinámico (botella whisky con esa etiqueta) y estático (póster en pared con esa etiqueta) en cada uno de los cuatro grupos experimentales. Durante la partida se utilizó un Eye Tracker Tobii X2-60 y se grabó la partida para determinar en el análisis posterior si el sujeto había tenido contacto visual con los estímulos objeto de estudio, para poder determinar si ha habido procesamiento de ellos o no. Tras jugar la partida, el sujeto realiza una prueba que incluye ítems de testado de las variables dependientes de procesamiento. 


\section{(SP) GRUPO CONTROL = sin marcas}

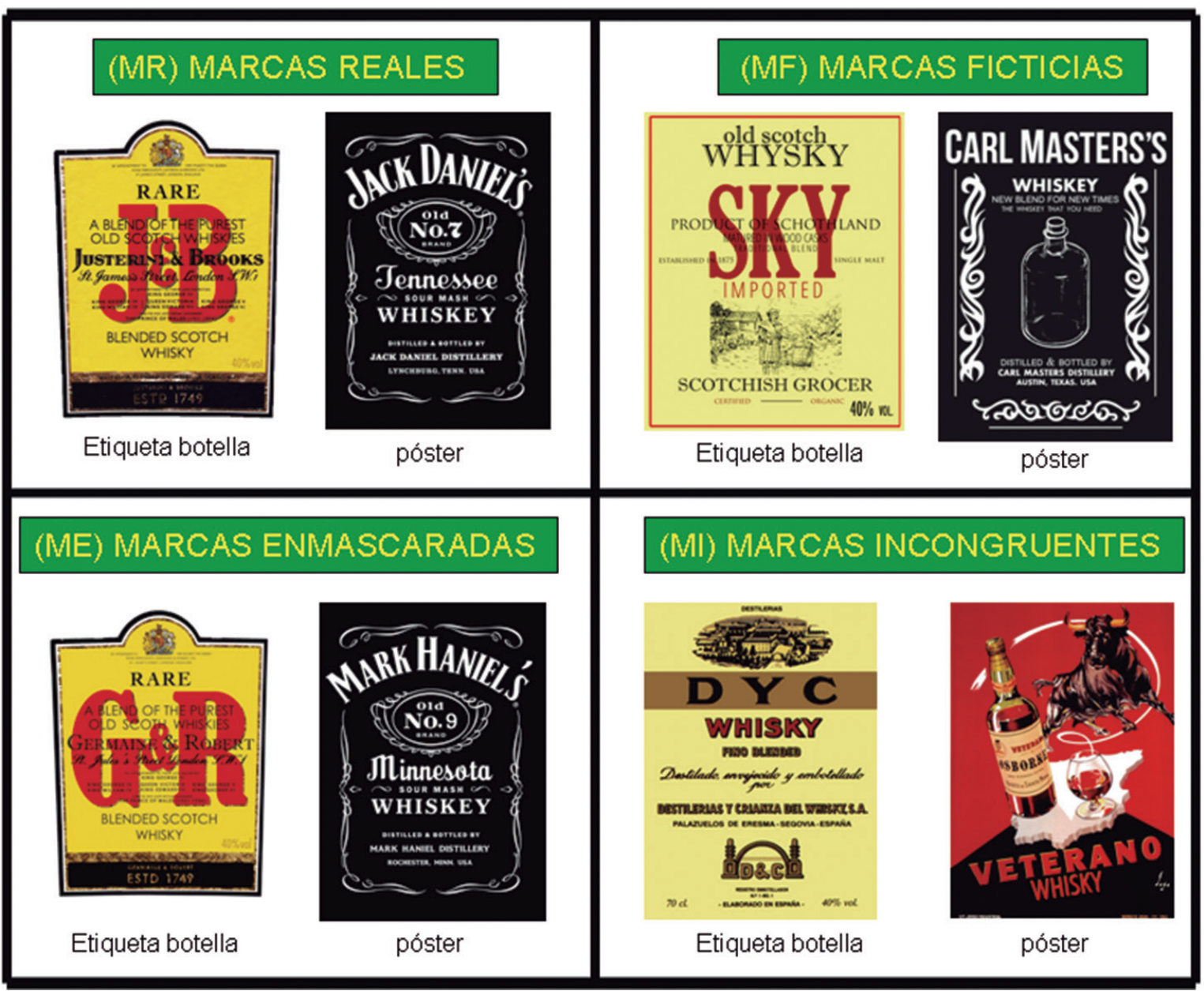

Figura 3. Marcas de los dos objetos estimulares dinámico (botella) y estático (póster) en los grupos experimentales

\section{Factores y variables experimentales}

Para la adecuada implementación de una metodología de respuesta multidimensional es necesario hacer un estudio preliminar a la investigación propiamente dicha que indague dos aspectos complementarios. Por un lado, es necesario identificar aquellas variables que se postula pueden intervenir en el proceso de eficacia publicitaria y que habrán de ser seleccionadas. Por otro lado, es necesario hacer un pretesteo con un grupo de sujetos para determinar la viabilidad del diseño en la ejecución del procedimiento experimental del objeto para descartar efectos de cansancio, rechazo y otras variables indeseables susceptibles de alterar las respuestas del sujeto. Esa labor 


\section{DISERTACIONES}

ESTUDIOS

Estudios de audiencias y recepción: audiencias minoritarias y nuevas mediaciones

ISSN: 1856-9536

Doi: http://dx.doi.org/10.12804/revistas.urosario.edu.co/disertaciones/v11i1

Volumen 11, Número 1 / Enero-junio 2018

Versión PDF para imprimir desde

http://revistas.urosario.edu.co/index.php/disertaciones

de testado y depuración de prueba ha dado lugar finalmente a un diseño definitivo cuya metodología multidimensional concreta es recogida aquí.

\section{Las variables independientes de diseño (VID)}

En la investigación se incluyen en el diseño 5 variables independientes que corresponden al tratamiento de los estímulos publicitarios incluidos en los grupos experimentales que juegan al videojuego:

- PRO: Prominencia dinámica: PROFo (focal) O PROPE (periférica): es dinámica en la medida en que la prominencia dependerá de la acción del jugador y no de la ubicación espacial en el encuadre del contenido.

- GIN: Grado de integración: GIN-P (en pantalla) o GIN-G (en guión);

- DIM: Dimensionalidad: DIM-BI (bidimensional/Jack Daniel's/Mark Haniel's) o DIM-TRI (tridimensional/J\&B/G\&R/ SKY/Dyc)

- EST: Estado: EST-es (estático/cuadro) o EST-dI (dinamizable/botella)

- TIME: Tipo de marca emplazada en el videojuego The Guest. Cinco modalidades:

i) TIME-SP = versión original sin publicidad

ii) TIME-MR = marca real emplazada (J\&B/Jack Daniel's)

iii) TIME-ME = marca enmascarada (G\&R/Mark Haniel's)

iV) TIME-MF = marca ficticia emplazada (sky/Carl Master's)

v) TIME-MI = marca incongruente en comparación con MF que es congruente con guión (Drc/Veterano Whisky)

Estas cinco variables independientes seleccionadas para el estudio de su eficacia publicitaria (EF) pueden agruparse en dos categorías:

1) Tipo de emplazamiento: en los estudios clásico de emplazamiento de producto el tipo de emplazamiento está definido y prefijado en el contenido con anterioridad. Sin embargo, en el presente videojuego, dados los importantes grados de libertad en la interactividad del jugador con el contenido, cualquier objeto emplazado es susceptible de actualizar un tipo u otro de procesamiento cognitivo por parte del jugador. Así, por ejemplo, desde el punto de vista de la prominencia, que un objeto adquiera la propiedad de ser focal o periférico dependerá de la conducta del jugador durante el juego. Por tanto, la categorización de un emplazamiento de producto se realiza en The Guest a posteriori y no a priori, como se venía haciendo en productos de entretenimiento clásicos, exentos de altos grados de interactividad. Para poder determinar de manera rigurosa si un jugador ha asimilado de un modo u otro el objeto utilizamos el eye tracker y la grabación de la partida para determinar qué y cómo estaba mirando el sujeto el objeto. Ello nos permitió saber con precisión el tipo de emplazamiento efectivo realizado.

Desde esta perspectiva tenemos, en conjunto, dos tipos de emplazamiento:

a) Favorable: aquel tipo de emplazamiento que ubica el objeto publicitario en un lugar privilegiado para aumentar las probabilidades de ser procesado por vía central o voluntaria. Este privilegio puede venir por diferentes vías. Por ejemplo si es colocado en una ubicación focal y no periférica (PROFO), si está integrado en el guión (GIN-G), si es tridimensional (DIM-TRI) o si es dinamizable durante el juego por parte del jugador (EST-DI).

En la presente investigación hablaremos de emplazamiento favorable cuando el jugador realice un procesamiento focal del estímulo publicitario (PROFO) e integre el producto en el guión, es decir, que manipule el objeto o le atribuya una función en el juego. En este caso el producto tendrá un grado de integración en guión (GIN-G). 


\section{DISERTACIONES}

ESTUDIOS

b) Desfavorable: aquel tipo de emplazamiento que ubica el objeto en un lugar poco visible o asequible, que disminuye las probabilidades de que este sea procesado por vía central y aumenta la de serlo por vía periférica o involuntaria. Este tipo de emplazamiento se ve cuando el objeto está ubicado en un espacio periférico (PROPE), SU grado de integración es meramente en pantalla, como parte del decorado (GIN-P), es bidimensional y no tridimensional (DIM-BI) o se encuentra durante el juego en un estado estático (EST-ES).

En la presente investigación hablaremos de emplazamiento desfavorable cuando el jugador realice un procesamiento periférico del estímulo publicitario (PROPE) y simplemente lo considere como integrado en pantalla, es decir, formando parte del decorado y el escenario sin tener una función en el relato (GIN-P).

En consecuencia, tanto el emplazamiento favorable como el desfavorable tienen que cumplir dos condiciones para que el emplazamiento sea considerado como tal.

Por otro lado, se analizó si hubo diferencias entre ambos tipos de emplazamiento en cuanto a su influencia sobre la EF. Veremos así si procesar el estímulo publicitario de manera favorable (o desfavorable) tiene algún efecto de eficacia sobre el procesamiento de la marca de whisky emplazada.

2) Tipo de marca: Un segundo factor de estudio en nuestro caso fue el tipo de marca emplazada según su estatuto real o ficcional. Veremos así si los emplazamientos, tanto favorables como desfavorables, produjeron resultados diferenciales entre los cuatro tipos de marca: real (MR), enmascarada (ME), ficticia (MF) o incongruente (мı). Dicho de otro modo, veremos si hay diferencias estadísticamente significativas entre los diferentes tipos de marca en función de los tres tipos de variables de eficacia publicitaria (EF-COG, EF-AF, EF-CON).

\section{Las variables moderadoras del individuo (VmI)}

Se trata de variables individuales antecedentes, susceptibles de moderar los efectos de los factores de entretenimiento y eficacia publicitaria (figura 2). He aquí las 8 testadas y la escala utilizada:

- App: actitud hacia el emplazamiento de producto en videojuegos (Nelson, Keum \& Yaros, 2004).

- cong: congruencia de la marca emplazada (Hernández, Chapa, Minor, Maldonado and Barranzuela, 2004)

- AFvI: afinidad con los videojuego (Perse, 1986)

- cono: conocimiento de marcas de whisky

- GAMER: jugador casual/jugador experto

- consum: consumo de bebidas alcohólicas

- Fam: familiaridad con el producto/marca whisky

- IMP: implicación con el producto (Zaichkowsky, 1994) / implicación con la marca (Varela, Rial, Braña \& de la Flor, 1998).

\section{Las variables dependientes: El entretenimiento (ENT)}

La experiencia de entretenimiento o disfrute audiovisual es un fenómeno multidimensional y por tanto es el resultado de la participación de diversas variables. Un producto cultural que nos entretiene es aquel por el que manifestamos interés: tenemos una mayor sensación de "estar ahí", absorbidos durante la experiencia, deseamos continuar exponiéndonos a ese contenido tanto durante como después de que finalice, sentimos emociones que nos procuran disfrute, sentimos empatía e identificación con el personaje, tenemos una sensación de flujo (flow). 


\section{DISERTACIONES}

ESTUDIOS

Por tanto, para aproximarse al entretenimiento hay que tener en perspectiva ese conjunto de fenómenos que participan en la experiencia de entretenimiento.

El conjunto de variables que hemos seleccionado para esta investigación, que constituyen una parte destacada de las que intervienen en el entretenimiento, pueden ser agrupadas en tres grupos en función del momento en que son solicitadas o según el momento en que intervienen en esa experiencia de conjunto. Tenemos así:

a) Antes de juego: Aquí nos interesamos por la motivación de juego. Antes de jugar, el sujeto tiene unas razones para participar en el juego que pueden ser extrínsecas (por ejemplo, tiene curiosidad de participar o simplemente le interesa para su curso académico) o intrínseca (por ejemplo, es un jugador experto/experimentado). En nuestro caso lo indagamos a partir de los resultados en las variables DEC-A (objetivos) y GAMER.

b) Durante el juego: Aquí nos interesamos por lo que ocurre durante el juego y la percepción que el sujeto tiene y su evaluación. Tenemos dos tipos de medida. Una que evalúa la experiencia durante el juego (variables ENG-EE/ TRANS/DEC-B,C,D/IDEN) y la otra que recoge la respuesta corporal durante el juego (BIO).

c) Después del juego: Aquí tenemos dos tipos de datos. Por un lado se evalúa el disfrute general experimentado (DEC-A / APR / ATV / PANAS Comparando PRET-POST). Por otro, se valora la percepción del jugador de su interacción con las interfaces, es decir, para jugar hay que interactuar con el juego y los dispositivos tecnológicos que nos permiten jugar (tales como teclados, etc.). En nuestro caso lo evaluamos mediante FAP/PAP/FRU/ENG-C.

Estas son las 11 variables de entretenimiento testadas (ENT):

- PPRE-PPos: panas pret/post (Gargurevich, 2010; Thompson, 2007)

- Bı: medidas emocionales con biofeedback (BFB-2000x-pert Schuhfried)

- APR: actitudes apreciativas de disfrute del videojuego (Ducoffe, 1996 a, b).

- ATv: actitud hacia el videojuego (Chattopadhyay \& Basu, 1990)

- FaP: facilidad percibida

- PAP: capacidad percibida para jugar con éxito (Bartholow, Sestir \& Davis, 2005)

- FRU: frustración (Bartholow, Sestir \& Davis, 2005)

- ENG: enganche (engagement) (Busselle \& Bilandzic, 2009)

- TRANs: transportación (Green \& Brock, 2000)

- IDEN: identificación (Cohen, 2001; Igartua \& Páez, 1998)

- DEC: deseo de continuación (Schoenau-Fog, 2014)

\section{Las variables dependientes: La eficacia publicitaria (EF)}

Finalmente, la medición de las variables dependientes de eficacia publicitaria se midió mediante ítems de tres tipos según la distinción entre evaluación de variables cognitivas, afectivas y conativas. He aquí las 11 variables de eficacia publicitaria testadas:

Variables cognitivas (EF-COG):

- PER: atención/perceptivas -indicadores de procesamiento estímulos (marcas) mediante eye tracker: prominencia/integración/estado-.

- Recuc: recuerdo de marcas a corto plazo / Recum: recuerdo a medio plazo: Icc (índice de conocimiento consciente de marcas) 


\section{DISERTACIONES}

ESTUDIOS

- IPI: índice de procesamiento inconsciente de marca. Se utiliza una batería de ítems que indagan el efecto priming (Bermejo \& Gil, 2016; Froufe et al. 2009).

- REcc: Reconocimiento de marcas a corto plazo / RECM: reconocimiento a medio plazo

Variables afectivas EF-AF:

- AMA: actitud hacia la marca (Spears \& Singh, 2004).

- IRR: irritabilidad por la presencia de la marca en videojuego (Ducoffe, 1996a; 1996b)

Variables conativas EF-CON:

- INT: intencionalidad de compra/uso (Homer, 1990; Mitchell \& Olson, 1981; Petty, Cacioppo \& Schumann, 1983)

- RCP: deseo de recibir una muestra del producto

- ELEc: elección entre otras marcas

La figura 4 recoge la secuencia de ejecución de las diferentes pruebas realizadas por el jugador:

-Antes de jugar: DEC-A/PPRE)

-Durante el juego: DEC-B)

-Después de jugar: PPOS / DEC-C/IPI1i / IPI1ie / IPI1v / IPI1ve / APR / ATV / RECUC / IPI2v / IPI2ve-EF-COG / IPI2MRP / IPI2MRPe / RECC / IPI3MRFi / IPI3MRFv / IPI3MRPi / IPI3MRPv / FAP / PAP / FRU AMA / IRR / ENG / TRANS / IDEN / DEC / INT / RCP / ELEC

-Siguiente semana: RECM / IPI11i / IPI11ie / IPI22MRF / IPI22MRFe / IPI22MRP / IPI22MRPe / RECUM / IPI33MRFi / IPI33MRFv / IPI33MRPi / IPI33MRPv / APP / CONG / AFVI / CONO / FAM / GAMER / CONSUM / IMP / DAPE

Figura 4. Secuencia de fases de ejecución de las pruebas

\section{Conclusión}

A partir de la constatación de la necesidad de introducir metodologías multidimensionales en los estudios de audiencia y recepción del entretenimiento mediático en general y, del advertainment en particular, con la finalidad de hacer avanzar la investigación en este campo, tres consideraciones se desprenden del modelo propuesto:

1. Entre otros factores, las nuevas formas de comunicación viral o el avance en la oferta de contenidos interactivos cada vez más participativos, están haciendo que las tipologías del advertainment (Russell, 2007) evolucionen en el mercado hacia una diversificación de experiencias con el usuario de los medios. Cada vez más los mensajes híbridos solicitan del receptor que participe de forma interactiva en la actividad de entretenimiento audiovisual. Cada una de estas nuevas y variadas experiencias requiere del usuario la activación de un nivel psicológico de procesamiento interactivo de los estímulos publicitarios a los que es expuesto durante la experiencia de entretenimiento, adaptada al tipo de interactividad que la actividad le solicita. 


\section{DISERTACIONES}

ESTUDIOS

Estudios de audiencias y recepción: audiencias minoritarias y nuevas mediaciones

ISSN: 1856-9536

Doi: http://dx.doi.org/10.12804/revistas.urosario.edu.co/disertaciones/v11i1

Volumen 11, Número 1 / Enero-junio 2018

Versión PDF para imprimir desde

http://revistas.urosario.edu.co/index.php/disertaciones

Tal y como hemos podido identificar, existen actualmente cuatro niveles de procesamiento psicológico de los mensajes híbridos de entretenimiento audiovisual (Bermejo, 2015; 2017). Esta mayor complejidad del fenómeno publicitario trae aparejada la necesidad de indagar con el mismo grado de complejidad la respuesta del usuario. La metodología multidimensional permite, como en el modelo presentado aquí, profundizar en el conocimiento de aquellos factores que dan cuenta del funcionamiento eficaz de la publicidad en productos de entretenimiento, en su relación con el receptor. Hay que tener en cuenta que, con este procedimiento metodológico, se mide en el sujeto tanto su procesamiento del estímulo publicitario durante la exposición al contenido de entretenimiento, como los efectos cognitivos, emocionales y comportamentales que engendra. Medir la recepción permite delimitar mejor si un contenido del advertainment lleva a la mera asimilación y recuerdo de la marca, como ocurre en el product placement o en cambio es incorporada por el jugador al proceso interactivo con el relato, lo que puede desembocar en procesos de construcción de marca (branding), por los que se interesa especialmente el branded entertainment.

Por tanto, la metodología multidimensional es una herramienta útil para discriminar los efectos de los diferentes tipos de advertainment. Para decidir si un producto era product placement o branded entertainment se han venido aplicando dos criterios (el tipo y grado de integración de la marca en el contenido o el agente que financia la producción, guión, edición y distribución del contenido). Estos criterios consideran las propiedades del contenido pero no la respuesta del receptor a ellos. El análisis que aporta la metodología multidimensional hace necesario que incorporemos un tercer criterio de discriminación, a saber, la respuesta multidimensional que permite determinar cuál ha sido el tipo y grado de procesamiento y los efectos del estímulo publicitario en el proceso interactivo descrito más arriba. Añade por tanto, a los criterios desde el mercadeo, un tercer criterio desde la comunicación y la psicología.

2. El modelo propuesto por Balasubramanian et al. (2006) supuso un avance para nuestra comprensión de la respuesta de la audiencia al emplazamiento de producto en mensajes híbridos de entretenimiento. El modelo de metodología multidimensional permite expandir aquel modelo a mensajes híbridos interactivos como el videojuego. Además, incorpora al análisis variables de procesamiento correspondientes a la respuesta corporal o psicofisiológica y conductual, así como variables dependientes incluidas en un factor general de entretenimiento.

3. La metodología multidimensional implica la integración en el diseño de la investigación de una configuración de respuestas del receptor en su interacción con el producto mediático. Ello permite, como acabamos de señalar, dotar de nuevas potencialidades a la investigación en recepción pero al mismo tiempo, dada su complejidad, puede acarrear también ciertas limitaciones si no se satisfacen algunos requerimientos o condiciones necesarias. En primer lugar, es pertinente realizar pretesteo (o disponer de resultados de investigación anteriores) en los que se indaguen aquellas variables susceptibles de contribuir a explicar los efectos a observar en la investigación propiamente dicha. En segundo lugar, hay que seleccionar aquellas variables principales que pueden ser incluidas en el diseño experimental sin que ello introduzca a su vez factores de distorsión de las respuestas (fundamentalmente por razones de exceso de demanda de tareas al participante en cada sesión o por incompatibilidad de pruebas entre sí). En tercer lugar se han de establecer los objetivos que definan con anterioridad la dinámica que se pretende establecer entre las diferentes variables y factores incluidos en la estructura de conjunto del modelo. Considerar estas restricciones implica poder beneficiarse de una metodología útil para el futuro recorrido de los estudios de audiencia y recepción.

\section{5}




\section{DISERTACIONES}

ESTUDIOS

\section{Referencias}

1. Balasubramanian, S. K. (1994). Beyond advertising and publicity: Hybrid messages and public policy issues, Journal of Advertising, 23(4), 29-46.

2. Balasubramanian, S. K., Karrh, J. A., \& Patwardhan, H. (2006). Audience response to product placements. An integrative framework and future research agenda. Journal of Advertising, 35(3), 115-141

3. Bartholow, B. D., Sestir, M. A., \& Davis, E. B. (2005). Correlates and consequences of exposure to videogame violence: Hostile personality, empathy and aggressive behavior. Personality and Social Psychology Bulletin, 31, 1573- 1586.

4. Bergillos García, I. (2015). Participación de la audiencia y televisión en la era digital. Propuesta de análisis y evolución de las invitaciones a la participación en la TDT y en otras plataformas. (Tesis doctoral, Bellaterra: Universitat Autònoma de Barcelona).

5. Berkowitz, L. (2012). A cognitive theory of aggression. En A. M. Paul, A. Van Lange, W. Kruglanski, \& E. Tory Higgins (Eds.). Handbook of theories of social psychology (pp. 99-118). London: Sage.

6. Bermejo-Berros, J. (2005). Narrativa audiovisual. Investigación y aplicaciones. Madrid: Ediciones Pirámide.

7. Bermejo-Berros, J. (2012). Perspectivas y falacias en la edición científica digital. Pensar la Publicidad, 6(2), 289-295.

8. Bermejo-Berros, J. (2013 a). El enmascaramiento como estrategia persuasiva en la publicidad para jóvenes, Comunicar, 41, 157-165.

9. Bermejo-Berros, J. (2013 b). Metodología multidimensional en la indagación del fenómeno complejo del entretenimiento hipermedia. En M. Vicente et al. (Coords.), Investigar la comunicación hoy: revisión de políticas científicas y aportaciones metodológicas (pp. 709-724). Segovia: Universidad de Valladolid.

10. Bermejo-Berros, J. (2014). Evolución de los paradigmas, metodologías y campos de la comunicación en Revista Latina de Comunicación Social durante la década 2004-2013. Revista Latina de Comunicación Social, 69, 330-353.

11. Bermejo-Berros, J. (2015). A classification of branded entertainment based on psychological levels of processing. En J. M. Parreno, C.R. Mafe, \& L. Scribner (Eds.), Engaging consumers through branded entertainment and convergent media (pp. 22-54). Hershey: IG Global.

12. Bermejo-Berros, J. (2017). A classification of branded entertainment based on psychological levels of processing. En M. Khosrow-Pour (Ed.), Advertising and branding: Concepts, methodologies, tools, and application (pp. 155-185). Hershey: IGI Global.

13. Bermejo, J., \& Soto-Sanfiel, M. T. (2011). Avances conceptuales en la dimensión pragmática de la narrativa audiovisual en el contexto multimedia. En F. García, \& M. Rajas (Coords.). Narrativas audiovisuales: el relato (pp.177-199). Madrid: Ícono.

14. Bermejo-Berros, J., \& López Díez, J. (2013). Sorpresa y diégesis en la teoría narrativa audiovisual. En P. Gómez (Coord.), Teorías y aplicaciones narrativas (pp. 131-161). Madrid: Ícono. 


\section{DISERTACIONES}

ESTUDIOS

Estudios de audiencias y recepción: audiencias minoritarias y nuevas mediaciones

ISSN: 1856-9536

Doi: http://dx.doi.org/10.12804/revistas.urosario.edu.co/disertaciones/v11i1

Volumen 11, Número 1 / Enero-junio 2018

Versión PDF para imprimir desde

http://revistas.urosario.edu.co/index.php/disertaciones

15. Bermejo-Berros, J., \& Gil, M.A. (2016). Influencia del procesamiento consciente e inconsciente de estímulos interactivos reales y ficticios en videojuegos. En A. A. Arvalho et al. (Eds.), Atas do $3^{\circ}$ encontro sobre jogos e mobile learing (pp. 119-131). Coimbra: Edición Universidad de Coimbra.

16. Bryant, J., \& Miron, D. (2006). Excitation-Transfer theory and three-factor theory of emotion. En J. Byant \& P. Vorderer (Eds.), Psychology of Entertainment (pp. 31-61). Mahwah: Lawrence Erlbaum.

17. Bryant, J., \& Vorderer, P. (Eds.), (2006). Psychology of entertainment. Mahwah: Lawrence Erlbaum.

18. Busselle, R., \& Bilandzic, H. (2009). Measuring narrative engagement. Media Psychology, 12(4), 321-347.

19. Cantor, J. (2011). Fear reactions and the mass media. En K. Döveling, C. Scheve \& E. A. Konijn (Eds.), The Routledge handbook of emotions and mass media. (pp. 148-166). Nueva York: Routledge.

20. Cascajosa Virino, C. (2016). Buscando al espectador serial desesperadamente: la nueva investigación de audiencias y la serie El Ministerio del Tiempo. Dígitos, 2, 53-69.

21. Chattopadhyay, A., \& Basu, K. (1990). Humour in advertising: The moderating role of prior brand evaluation. Journal of Marketing Research, 27(4), 466-476.

22. Cohen, J. (2001). Defining identification: A theoretical look at the identification of audiences with media characters. Mass Communication \& Society, 4(3), 245-264.

23. Ducoffe, R. H. (1996a). Advertising value and advertising on the web. Journal of Advertising Research, 36(5), 21-35.

24. Ducoffe, R. H. (1996b). How consumers assess the value of advertising. Journal of Current Issues and Research in Advertising, 17, 1-18.

25. Fernández, C. (2016). Comscore y kANTAR desvelan cómo será la medición de audiencias crossmedia del futuro. Recuperado de http://prnoticias.com/marketing/espacio-marketing/20149577-comscore-kantarmedicion-audiencias-acuerdo

26. Froufe, M. Sierra, B., \& Ruíz, M.A. (2009). El inconsciente cognitivo en la psicología científica del siglo xxı. Extensión Digital, 1, 1-22.

27. Fuenzalida, V. (2006). Estudios de audiencia y recepción en Chile. Diálogos de la Comunicación, 73, 40-45.

28. Gargurevich, R. (2010). Propiedades psicométricas de la versión internacional de la Escala de Afecto Positivo y Negativo-forma corta (I-Spanas SF) en estudiantes universitarios. Persona, 13, 31-42.

29. Green, M., \& Brock, T.C. (2000). The role of transportation in the persuasiveness of public narratives. Journal of Personality and Social Psychology, 79(5), 701-721.

30. Homer, P.M. (1990). The mediating role of attitude toward the ad: Some additional. Journal of Marketing Research, 27(February), 78-86.

31. Hernández, M.D., Chapa, S., Minor, M.S, Maldonado, C. Y., \& Barranzuela, F. (2004). Hispanic attitudes toward advergames: A proposed model of their antecedents. Journal of Interactive Advertising, 5(1), 74-83.

32. Hudson, S., \& Hudson, D. (2006). Branded entertainment: A new advertising technique or product placement in disguise? Journal of Marketing Management, 22(5-6), 489-504.

33. Huertas, A. (2009). La audiencia investigada. Barcelona: Gedisa.

34. Igartua, J. y Páez, D. (1998). Validez y fiabilidad de una escala de empatía e identificación con los personajes. Psicothema, 10(2), 423-436. 


\section{DISERTACIONES}

ESTUDIOS

35. Igartua, J. J (2013). Impacto actitudinal y canalización cognitiva de estereotipos sobre la inmigración a través de las noticias. Revista Latina de Comunicación Social, 68, 599-621.

36. Jacks, N. D. Escosteguy (2006). La investigación brasileña: impases y desafíos. Diálogos de la Comunicación, 73, 37-45.

37. Jensen, J.F. (1998). "Interactivity". Tracking a new concept in media and communication studies. Nordicom Review, 1, 185-204.

38. Karim, J., Wiesz, R., \& Rehman, S. U. (2011). International positive and negative affect schedule short-form (I-PANAS-SF): Testing for factorial invariance across cultures. Procedia Social and Behavioral Sciences, 15, 2016-2022.

39. Kiousis, S. (2002). Interactivity: A concept explication. New Media \& Society, 4(3), 355-383.

40. Klimmt, C., Hartmann, T., \& Schramm, H. (2006). Parasocial interactions and relationships. En J. Byant, \& P. Vorderer (Eds.), Psychology of Entertainment (pp. 291-315). Mahwah: Lawrence Erlbaum.

41. Klimmt, C., \& Vorderer, P. (2009). Media entertainment. En C. R. Berger, M. E. Roloff \& D. Roskos-Ewoldsen (Eds.), The handbook of communication science (pp. 345-361). Thousand Oaks: Sage.

42. Knobloch-Westerwich, S. (2006). Mood Management: Theory, evidence, and advancements. En J. Byant, \& P. Vorderer (Eds.), Psychology of Entertainment (pp. 239-254). Mahwah: Lawrence Erlbaum.

43. Koolstra, C.M., \& Bos, M.J.W. (2010). The development of an instrument to determine different levels of interactivity. International Communication Gazette, 71(5), 373-91.

44. Landay, L. (2014). Interactivity. En M.J.P. Wolf, \& B. Perron (Eds.), The Routledge companion to video game studies (pp.173-184). Londres: Routledge.

45. Martí Parreño, J. (2011). Propuesta de una herramienta de análisis de contenido para el emplazamiento de producto en contenidos audiovisuales, Pensar la Publicidad, 5(2), 65-92.

46. Martín-Barbero, J., \& Tellez, P. (2006). Estudios de recepción y consumo en Colombia, Diálogos de la Comunicación, 73, 57-69.

47. Nelson, M.R., Keum, H., \& Yaros, R.A. (2004). Advertainment or adcreep game player's attitudes toward advertising and product placements in computer games, Journal of Interactive Advertising, 5(1), 3-21.

48. Oliver, M. B. (2003). Mood management and selective exposure. En J. Bryant, D. Roskos-Ewoldsen, \& J. Cantor (Eds.), Communication and emotion: Essays in honor of Dolf Zillmann (pp. 85-106). Mahwah: Erlbaum.

49. Orozco Gomez, G. (2000). Travesías y desafíos de la investigación de la recepción en América Latina. Comunicación y Sociedad, 38, 11-36.

50. Orozco Gomez, G. (2003). Los estudios de recepción: de un modo de investigar, a una moda, y de ahí a muchos modos. UFRGS, 2(9), 1-13.

51. Padilla de la Torre, M., \& Orozco Gómez, G. (2006). Estudios de recepción en México: un itinerario. Diálogos de la Comunicación, 73, 133-144.

52. Perse, E.M. (1986). Soap opera viewing patterns of college students and cultivation. Journal of Broadcasting and Electronic Media, 30(2), 175-193.

53. Quintas Froufe, N. \& González Neira, A. (Coords.) (2015). La participación de la audiencia en la televisión: de la audiencia activa a la social. Madrid: Almc, Asociación para la Investigación de Medios de Comunicación 


\section{DISERTACIONES}

ESTUDIOS

Estudios de audiencias y recepción: audiencias minoritarias y nuevas mediaciones

ISSN: 1856-9536

Doi: http://dx.doi.org/10.12804/revistas.urosario.edu.co/disertaciones/v11i1

Volumen 11, Número 1 / Enero-junio 2018

Versión PDF para imprimir desde

http://revistas.urosario.edu.co/index.php/disertaciones

54. Rafaeli, S. (1988). Interactivity. From new media to communication. En R.P. Hawkins, J.M. Wiemann, \& S. Pingree (Eds.), Advancing Communication Science: Merging Mass and Interpersonal Processes (pp. 110134). Newbury Park: Sage.

55. Raney, A. A. (2006). The Psychology of Disposition-Based Theories of Media Enjoyment. En J. Byant, \& P. Vorderer (Eds.), Psychology of entertainment (pp. 61-85). Mahwah: Lawrence Erlbaum.

56. Schoenau-Fog, H. (2014). At the core of player experience: Continuation desire in digital games. En M.C. Angelides \& H. Agius (Eds.), Handbook of digital games (pp. 388-411). Nueva Jersey: IEEE Press-Wiley.

57. Shrum, L.J. (2006). Perception. En Psychology of entertainment. En J. Byant, \& P. Vorderer (Eds.), Psychology of entertainment (pp. 55-69). Mahwah: Lawrence Erlbaum.

58. Soto-Sanfiel, M.T., Aymerich-Franch, L., \& Ribes-Guàrdia, F.X. (2009). Interactividad y contenido como factores de disfrute en las ficciones interactivas. Revista Latina de Comunicación Social, 64, 668-681.

59. Souza, M.D. (Ed.). (2014). Los desafíos de la audiencia televisiva como sujeto de estudio. Santiago de Chile: Consejo Nacional de Televisión.

60. Spears, N., \& Singh, S. (2004). Measuring attitude toward the brand and purchase intentions. Journal of Current Issues and Research in Advertising, 26(2), 53-66.

61. Steuer, J. (1995). Defining virtual reality: Dimensions determining telepresence. En F. Biocca, \& M.R. Mark (Eds.), Communication in the age of virtual reality (pp. 33-56). Hillsdale: Lawrence Erlbaum.

62. Thompson, E.R. (2007). Development and validation of an internationally reliable short-form of the Positive and Negative Affect Schedule (PANAS). Journal of Cross-Cultural Psychology, 38, 227-242.

63. Valkenburg, P., \& Jochen, P. (2006). Fantasy and imagination. En J. Byant, \& P. Vorderer (Eds.), Psychology of entertainment (pp. 105-117). Mahwah: Lawrence Erlbaum.

64. Varela, J., Rial, A., Braña, T., \& de la Flor, M. (1998). Presentación del єм: un instrumento para medir la implicación de 1os consumidores con marcas comerciales. Anuario de Psicología, 29(1), 17-33.

65. Vorderer, P. (2003). Entertainment theory. En J. Bryant, D. Roskos-Ewolden, J. Cantor (Eds.), Communication and Emotion (pp. 131-155). Mahwah: Lawrence Erlbaum.

66. Vorderer, P., Wulff, H. J., \& Friedrichsen, M. (Eds.). (1996). Suspense. Conceptualizations, theoretical analyses, and empirical explorations. Mahwah: Lawrence Erlbaum.

67. Wallon, H. (1934). Les origines du caractère chez l'enfant. Paris: Puf.

68. Zaichkowsky, J.L. (1994). The Personal involvement inventory: Reduction, revision, and application to advertising, Journal of Advertising, 23(4), 59-70.

69. Zillmann, D. (1988). Mood management through communication choices. American Behavioral Scientist, 31 (3), 327-341.

70. Zillmann, D. (2000a). Mood management in the context of selective exposure theory. En Roloff, M. E. (Ed.), Communication yearbook, 23 (pp. 103-123). Thousand Oaks: Sage.

71. Zillmann, D. (2003). Theory of affective dynamics: Emotions and moods. En J. Bryant, D. Roskos-Ewolden, \& J. Cantor (Eds.), Communication and emotion. Essays in honor of Dolf Zillmann (pp. 533-567). Mahwah: Lawrence Erlbaum. 